\title{
Turismo e Estâncias: Impactos Positivos ${ }^{1}$
}

\author{
Madalena Pedroso Aulicino²
}

\begin{abstract}
RESUMO: Este artigo procura avaliar de maneira quantitativa alguns dos impactos socioeconômicos da atividade turistica sobre municipios paulistas. Amparado por técnicas estatisticas, o estudo demonstra que. alím de serem passiveis de quantificação, os impactos do turismo são fav'oráveis à geração de riqueza, de empregos e mesmo à condição de vida da população receptora, segundo alguns indicadores.
\end{abstract}

PALAVRAS-CHAVES: Turismo; impactos socioeconômicos; avaliação quantitativa;estâncias; São Paulo; Brasil.

ABSTRACT: This article proposes a quantitative analysis of some socio economic impacts due to tourism in some counties of São Paulo State. Using statistical techniques, this study demonstrates ihat tourism impacts are not only mensurable, but also favor richness and employment creation, as well as propitiate a better living condition to the receptive population. as shown by' some indicators.

KEYWORDS: Tourism: socioeconomicimpacts; quantitative evaluation: Sao Paulo State counties; São Pau!o; Brasil.

\section{INTRODUÇÃO}

De uma forma geral, a avaliação dos impactos da atividade turistica enfrenta uma série de desafios. Um deles refere-se à dificil delimitação entre fatores intervenientes e impactos gerados por essa atividade: espécie

1. Síntese da Dissertação de Mestrado da autora, defendida em outubro de 1994, na Escola de Comunicações e Artes da UISP (Aulicino, 1994)

2. Mestre em Cièncias da Comunicação pela Escola de Comunicições e Artes da L'niversidade de São Paulo. Prefessora dos Cursos de Turismo da Faculdade Alembi Morumbi e da Universidade Paulista.

End. para Corresp.: Rua Despraiado, 89, Chácara Santo Antònio, 04711 - São Paulo - SP Brasil. 
de vetores de interação mútua, muitas vezes ambos se confudem, dificul. tando o trabalho do pesquisador. Por exemplo: as condições naturais cons. tituem-se num fator de atração de fluxos turísticos, cnquanto a então des controlada exploração do ambiente pode atuar como fator de repulsão

Além disso, é difícil estabelecer com exatidão quais os impactos pro vocados pelo turismo e quais os que podem ser cxplicados por outras or. dens de fatores. Por outro lado, é preciso considerar ainda a importância da atividade turística para a cconomia do país como um todo, além do se॥ grau de integração com os outros setores econômicos (Rabahy, 1990). No caso do Brasil, esse fato é especialmente agravado pelo recente desenvolvimento do setor e pela ainda mais recente abordagem científica do fênomeno, aliados à quase total ausência de dados estatísticos.

Apesar disso, este artigo procura avaliar de uma maneira quantitativa alguns impactos socioeconômicos do turismo sobre as Estâncias do Es. tado de São Paulo, quando comparadas a outros municípios paulistas. Scrão positivas nesse sentido as repercussões da atividade turística? - É 0 que se pretende demonstrar.

\section{IMPACTOS DO TURISMO}

Muitos autores têm realizado estudos e proposto classificações dos impactos da atividade turistica, como Rabahy (1990) que os agrupa cm cconômicos, socioculturais c ambientais. Entre os impactos econômicos cstão incluídos, por excmplo, a geração e a distribuição de renda e o aumento do nível de empregos. Já os socioculturais referem-se à formação de recursos humanos e às mudanças socioculturais $\mathrm{e}$ de hábitos de consumo. Finalmente, os impactos ambientais devem incluir, segundo Mathieson \& Wall (1991), aqueles que provocam transformações também nos ambientes criados pelo homem. É importante lembrar, ainda, que o conceito de ambiente nos dias de hoje abrange não só a interação num determinado espaço de fatores físicos, químicos e biológicos, mas também o homem, a comunidade humana que ali vive com seus valores, sua maneira de ser

Quanto à avaliação desses impactos, vale dizer que são concomitantemente positivos e negativos, sendo muito dificil chegar-se a um resultado "líquido"que ampare a definição de uma posição ideal de cxploração em impactos econômicos, culturais c ambientais (ou outros) atende antes a necessidades didáticas e de pesquisa, porque na realidade apresentam-se em interação continua. Além disso, alguns desses aspectos são muito difíceis de serem avaliados, como as transformações culturais ambientais que cxigem, por sua própria natureza, um tempo longo de ob- servações muito mais complexas pela quantidade de fatores envolvidos.

Por isso tudo é que se optou por um estudo que avaliasse Por impactos socioeconômicos do turismo numa escala quantit, no âmbito de municípios, como um trabalho pioneiro.

\section{ESTÂNCIAS COMO GRUPO DE ESTUDO}

Para a realização da pesquisa, escolheu-se como grupo de estudo o conjunto das estâncias do Estado de São Paulo que, cm setembro de 1993, conjunto das 44 municípios. As estâncias são definidas pela Secretaria de perfaziam e Turismo (1972) como "municípios privilegiados que além de Esportes esurais especificos, clima benéfico e paisagens notáveis ofererecursos nalor histórico, artístico ou religioso. Estão classificadas cm balncárias, turísticas, hidronuneirais e cligioso . Estáticas.
máticas

As estâncias têm com o turismo uma relação mais ou menos remota ma vez que não foram criadas com essa finalidade, já que o termo estância esteve sempre associado antes à questão da saúde e do repouso, e posteriormente ao turismo, pelos deslocamentos e infra-estrutura que implicam no atendimento coletivo e público desses objetivos. Além disso, até a Constituição de 1988 os seus prefeitos eram nomeados pelo governador do Estado e ainda hoje recebcm uma dotação orçamentária especial que costuma ser atraente, principalmente para os municipios muito pequenos.

\section{DEFINIÇÃO DO GRUPO DE CONTROLE}

Estabelecido o grupo de estudo, constituiu-se um grupo de controle que pudesse servir de parâmentro para as necessárias comparações e garantia de validade dos resultados obtidos. Esse grupo foi composto a partir de outros 44 municípios escolhidos também dentro do Estado de São Paulo, com base nos seguintes critérios:

a) tamanho equivalente de população, dentro das seguintes faixas, segundo classificação do IBGE (1988): até 20.000 hab.; de 20.001 a 100.000 hab.; de 100.001 a 500.000 hab.;

b) localização numa mesma região de forma a garantir uniformidade de condições geográficas, de acesso e de distância da capital paulista;

c) período de mais de dez anos de autonomia administrativa. 
Foram inevitáveis algumas restrições ao processo de emparelhamen. to de cada estância a um definido municipio "contraste". Além disso. afora o fator causal turismo, especialmente para as estâncias balneárias. de características intrinsecamente diferenciadas, tem-se as peculiaridades de alguns municipios do grupo de controle que apresentam clevada importância no setor terciário, resultante do crescimento de seu parque industrial. como os casos de Cubatão, São Bernardo do Campo c São Cactano do Sul. Nas Tabelas 1 e 2 apresentam-se os municípios pesquisados c algumas de suas características.

\section{DEFINIÇÃO E DESCRIÇÃO DAS VARIÁVEIS}

A partir do propósito inicial foram escolhidas para comparação algumas variáveis operacionais que se concentraram em torno da receita dos municípios, do pessoal empregado em comércio e serviços, do consumo de cnergia elétrica e dos terminais telefônicos. Esses dados foram coletados tendo por base o ano de 1990), com exceção das informações relativas ao domicílio de uso ocasional, que foram obtidas através dos dados preliminares do Censo Demográfico de 1991, pela quebra de periodicidade do último censo. Os dados foram normalmente cxpressos em termos "per capita"ou cm percentual, de forma a tornar comparáveis os indicadores selecionados. Para facilitar o tratamento estatístico c a apresentação dos resultados, as variáveis foram associadas a códigos, os quais são explicitados a seguir.

A Receita Municipal Própria "per capita” - RECMUNPI. corresponde à arrecadação de competência direta da própria Prefeitura c se concentra nos seguintes impostos municipais: IPTU (Imposto Predial c Territorial Urbano); ISS (Imposto sobre Serviços de Qualquer Nature\%a): c. a partir da Constituição de 1988. ITBI (Imposto sobre a Transferência de Bens Móveis "Inter-Vivos") c IVVC (Imposto sobre a Venda a Viarcjo de Combustíveis Líquidos e Gasosos). Inclui tambćm taxas. contribuições de melhoria e outras receitas de capital.

O percentual de Pessoal Ocupado em Comércio e Serviços em relàção à população Total - \% OCUPCOI - diz respeito ao volume médio anual de cmpregados contratados de acordo com as normas legais, ou scja. com cartcira assinada.

O percentual de Consumo Residencial de Energia Elétrica em relação ao Cosumo Total - CONS RES - corresponde ao consumo das unidä des residenciais urbanas, incluídas as instalações de uso comum de prédio ou conjunto $\mathrm{em}$ que predomine esse tipo de unidade.

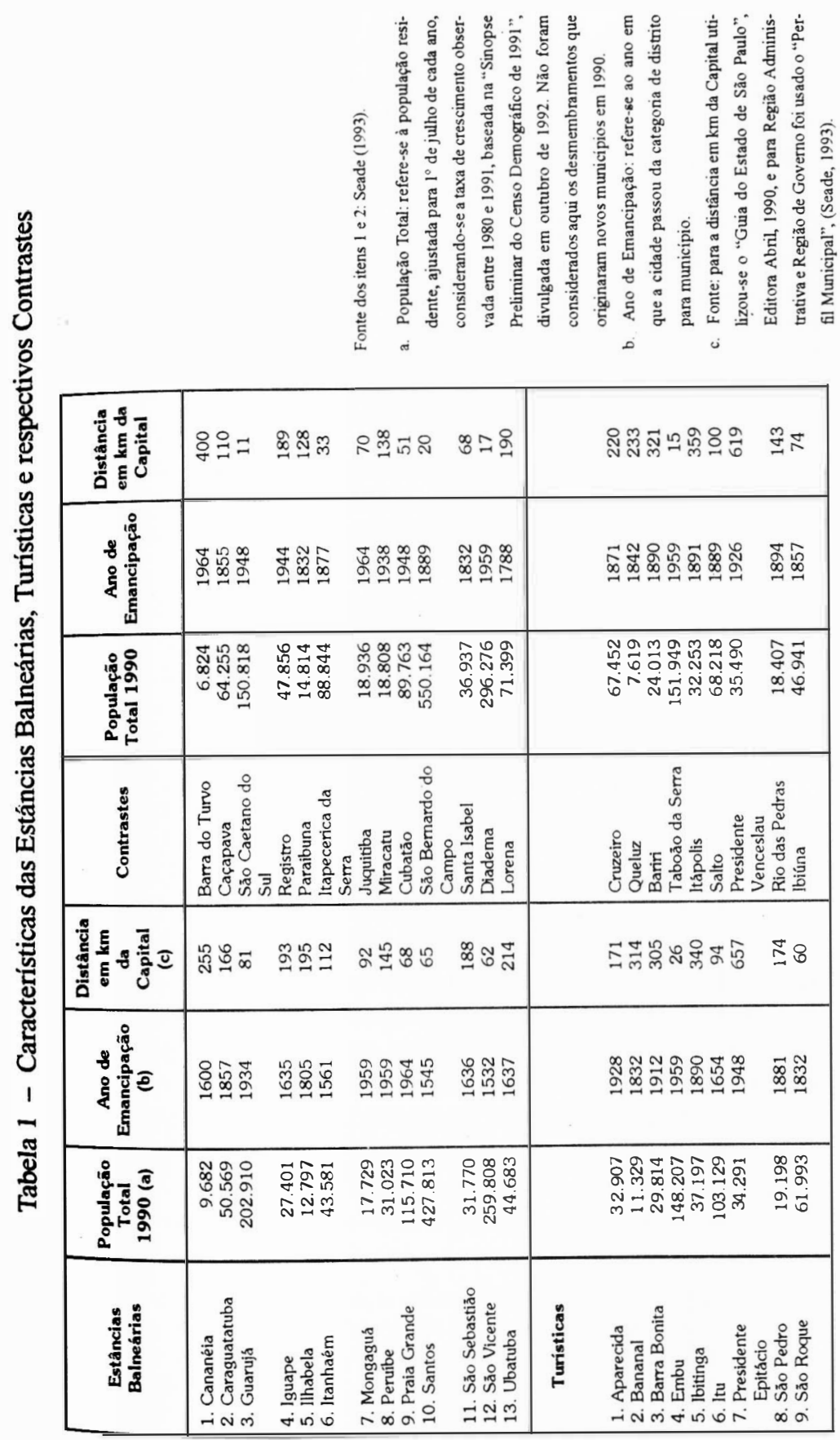




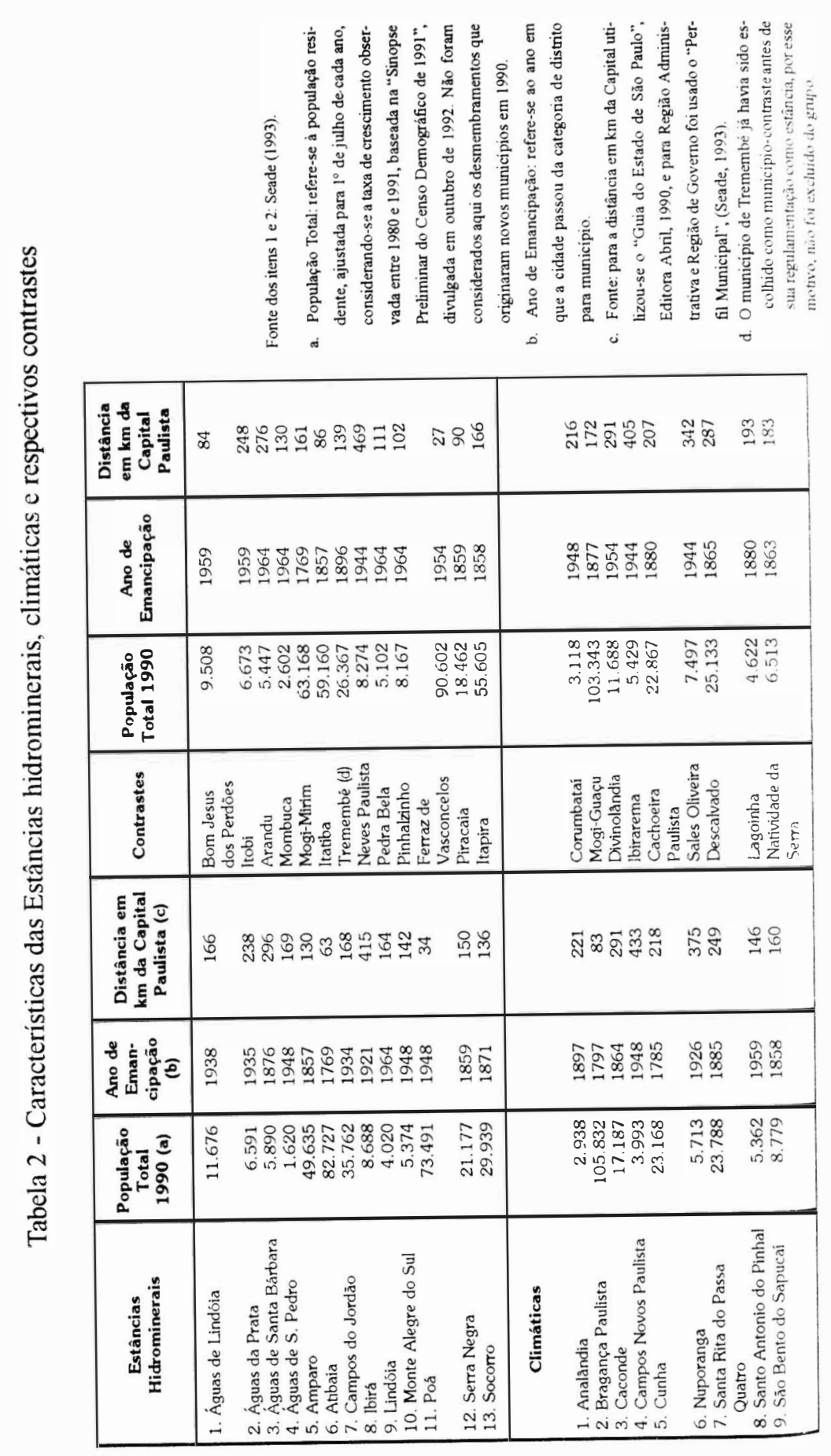

Já o percentual de Consumo de Energia Elétrica no Comércio, Servi$\cos$ e outras atividades, cm relação ao Consumo Total - CONS_COM refere-se ao consumo daquelas unidades em que são desenvolvidas atividades comerciais ou de prestação de serviços (excluidos os serviços públicos de água, esgoto, saneamento, tração elétrica urbana e/ou ferroviária) ssim como outras atividades que não se enquadram nas demais classes.

Os Terminais Telefonnicos por mil habitantes - TELEFONE - referem-se aos terminais $\mathrm{cm}$ serviços ligados a centrais locais e gerando reccita operacional. Incluem-se aqui os residenciais, não-residenciais, troncos e terminais de uso púbiicc

As cinco variáveis acima descritas tiveram seus dados coletados junto ao Seade (1993).

O percentual de Domicilios de Uso Ocasional em relação ao total de Domicilios - DOM_OC - foi obtido junto ao IBGE (1993), que considera domicilio, a moradia estruturalmente independente, constituida por um ou mais cômodos, com entrada privativa. Por extensão, edifícos em construção, embarcações, veículos, barracas, tendas, grutas c outros locais que estavam, na data do Censo. servindo de moradia, também foram considerados domicilios. Já o Domicílio de Uso Ocasional diz respeito ao domicílio particular que servia ocasionalmente de moradia (casa ou apartamento), isto é, os usados para descanso de fim-de-semana, férias ou outro fim

Finalmente a variável Quartos "per capita", PQUARTOS, corresponde à capacidade hoteleira dos municipios e inclui quartos, apartamentos e chalés, cujos dados foram extraidos do Censo Cultural - São Paulo (1990).

Todas essas variáveis tiveram suas médias comparadas por grupo de estâncias e de contrastes, através do teste não-paramétrico de MannWhitney, porque um método estatístico pré-aplicado, o "box-plot" (Bussab, 1984), revelou que as variáveis não tinham uma distribuicão normal, sendo 0 que se recomenda nesses casos. ${ }^{3}$ Os resultados foram favoráveis ao grupo das estâncias, como pode-se verificar na Tabela 3 .

Da observação dessa Tabela, pode-se apreender que as variáveis relacionadas apresentaram médias superiores e resultados estatisticamente significantes para o grupo das estâncias. No caso do DOM OC c PQUARTOS, ambas refletem fluxos turisticos, de onde deduz-se que a

3. Antes de realizar

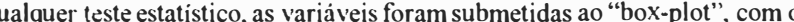
objetivo de conhecer o comportamento dos dados. O "box-plot" è construido utilizando-se a mediana como medida de posição central dos valores e o intervalo interquartil como medida de dispersão. A disposição desses valores num retàngulo fornece idéias de posição, dispersão referidria, caudas e dados discrepantes. Para maiores esclarecimentos, consultar a bibliografia 
Tabela 3 - Comparação de Médias de Variáveis Resumo dos testes " $t$ " e de Mann-Whitney

\begin{tabular}{|c|c|c|c|c|c|c|}
\hline & \multirow[b]{2}{*}{$\underset{\text { (a) }}{\text { GRUPO }}$} & \multirow[b]{2}{*}{ MÉDIA } & \multirow{2}{*}{$\begin{array}{l}\text { DESVIO } \\
\text { PADRÃO }\end{array}$} & \multicolumn{3}{|c|}{ NIVEL DESCRITIV() } \\
\hline & & & & t_Student & $\begin{array}{l}\text { Mann- } \\
\text { Whitney' }\end{array}$ & $\begin{array}{l}\text { Comparação } \\
\text { das médias bo }\end{array}$ \\
\hline RECMUNPI & $\begin{array}{l}1 \\
2\end{array}$ & $\begin{array}{l}32.78 \\
21.40\end{array}$ & $\begin{array}{l}32.55 \\
25.43\end{array}$ & 0.07 & $\begin{array}{r}0.02 \\
*\end{array}$ &.$^{1>2}$ \\
\hline$\%$ OCUPCO1 & $\begin{array}{l}1 \\
2\end{array}$ & $\begin{array}{l}9.34 \\
7.09\end{array}$ & $\begin{array}{l}6.04 \\
4.45\end{array}$ & 0.06 & $\begin{array}{r}0.05 \\
*\end{array}$ & $1>2$ \\
\hline DOM_OC & $\begin{array}{l}1 \\
2\end{array}$ & $\begin{array}{r}21.03 \\
6.56\end{array}$ & $\begin{array}{r}18.62 \\
6.65\end{array}$ & $\begin{array}{r}<0.01 \\
*\end{array}$ & $\begin{array}{r}<0.01 \\
*\end{array}$ & 12 \\
\hline TELEFONE & $\begin{array}{l}1 \\
2\end{array}$ & $\begin{array}{r}101.01 \\
64.51\end{array}$ & $\begin{array}{l}57.93 \\
35.55\end{array}$ & $\begin{array}{r}<0.01 \\
*\end{array}$ & $\begin{array}{r}<0.01 \\
*\end{array}$ & $1>2$ \\
\hline CONS_RES & $\begin{array}{l}1 \\
2\end{array}$ & $\begin{array}{l}44.71 \\
32.47\end{array}$ & $\begin{array}{l}16.29 \\
16.94\end{array}$ & $\begin{array}{r}<0.01 \\
*\end{array}$ & $\begin{array}{r}<0.01 \\
*\end{array}$ & $1>2$ \\
\hline CONS_COM & $\begin{array}{l}1 \\
2\end{array}$ & $\begin{array}{r}17.29 \\
9.46\end{array}$ & $\begin{array}{r}11.73 \\
6.49\end{array}$ & $\begin{array}{r}<0.01 \\
*\end{array}$ & $\begin{array}{r}<0.01 \\
*\end{array}$ & $1>2$ \\
\hline PQUARTOS & $\begin{array}{l}1 \\
2\end{array}$ & $\begin{array}{l}0.0180 \\
0.0005\end{array}$ & $\begin{array}{l}0.051 \\
0.001\end{array}$ & $\begin{array}{r}0.03 \\
*\end{array}$ & $\begin{array}{r}<0.01 \\
*\end{array}$ & $1>2$ \\
\hline
\end{tabular}

Obs.

a. Grupo: 1-Estància; 2-Contrastc

b. Resultado estatisticamente significante ao nivel de $5 \%$ iảo das estâncias com o turismo é significativa, atenuando-se assim as relacensões quanto às restrições que recairam sobre a escolha desse grupo.

Por outro lado, o favorecimento para as estâncias das variáveis RECMUNPI e \%OCUPCOI responde a indagações anteriores de que o turismo gera riqueza (através da arrecadação de impostos e salários) e empregos no setor terciário (comércio e serviços). Já o CONS_COM reveuma intensificação das atividades desse mesmo setor da economia tão associado à atividade turística.

Finalmente, os resultados favoráveis apresentados pelas variáveis TELEFONE e CONS_RES refletem uma melhor condição de vida da população das estâncias, porque não é raro serem utilizados com essa finaldade, ou seja, como indicadores de desenvolvimento (Andrade, 1991).

Fica então demonstrado, através dos resultados estatísticos obtidos para essas sete variáveis, que são positivas as repercussões ou impactos socioeconômicos da atividade turística sobre as estâncias do Estado de São Paulo.

\section{CONSIDERAÇÕES FINAIS}

É possivel avaliar impactos do turismo através de métodos quantitativos. Através desses mesmos métodos demonstrou-se que o turismo gera riqueza, empregos e mesmo uma melhor condição de vida para a populacăo receptora dos fluxos turísticos, segundo alguns indicadores. O conjunto das Estâncias do Estado de São Paulo está vinculado ao turismo de uma forma globalmente positiva. Ele lhes é benéfico e elas não seriam o que são hoje senão fosse pelo turismo, porque estão comparativamente em melhor situação que outros municipios de características semelhantes.

\section{REFERÊNCIAS BIBLIOGRÁFICAS}

ANDRADE, Manuel Correia de. Geografia econômica. 1991. São Paulo: Atlas

AULICINO, Madalena Pedroso 1994. Alguns impactos sócio-econômicos da atividade turistica sobre municipios paulistas. São Paulo: ECA/USP, 113 p. (Dissertação de Mestrado)

BUSSAB, Witton; MORETTIN, Pedro A. 1984. Métodos quantitavos para economistas e administradores. Estatistica básica. 2a ed. São Paulo: Atual, p. 32-3.

BGE - Fundação Instituto Brasileiro de Geografia e Estatistica 1988. Brasil: uma visāo geográfica dos anos 80. Rio de Janeiro: IBGE, 1988, p. 26.

BBGE - Fundação Instituto Brasileiro de Geografia e Estatistica 1993. Sinopse preliminar do 
censo demografico 1991. n. 19. São Paulo: IBGE.

MATHIESON, A.; WALL, G. 1990. Turismo. Repercusiones economicas, fisicas tyales. México: Trillas, p. 155-6.

RABAIIY, Wilson Abrahão. 1990. Planejamento do turismo. Estudos económicos e fut the imen. tos econométricos. São Paulo: Loyola, p. 55-79.

SEADE - Fundação Sistema Estadual de Análise de Dados. 1993. Perfil municipal. 198() Sào Paulo: Seade, $8 \mathrm{v}$.

SEST-Secretaria de Esportes e Turismo. Coordenadoria de Turismo. Estancias. Vários d. ritos (mimeo)

SECRETARIA DE ESTAD() DA CULTURA. Fundação Prefeito Faria Lima. 1990. Cimu (u. tural São Paulo 1990): litoral e interior. Secretaria de Estado de Cultura: São Paut. 